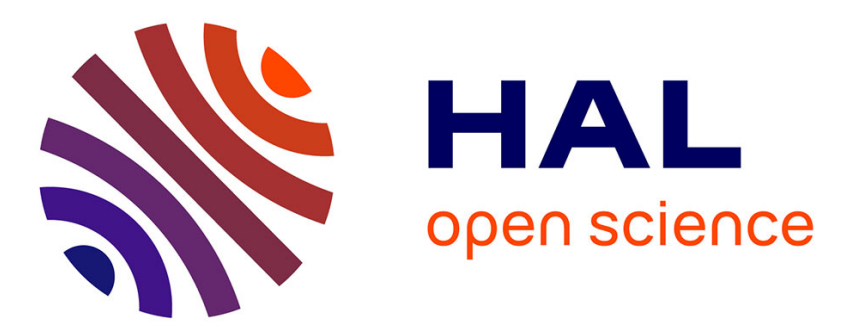

\title{
Fluorescence microscopy evidence for two different LE-LC phase transitions in Langmuir monolayers of fatty acids
}

Silvère Akamatsu, F. Rondelez

\section{- To cite this version:}

Silvère Akamatsu, F. Rondelez. Fluorescence microscopy evidence for two different LE-LC phase transitions in Langmuir monolayers of fatty acids. Journal de Physique II, 1991, 1 (10), pp.1309-1322. 10.1051/jp2:1991134 . jpa-00247592

\section{HAL Id: jpa-00247592 https://hal.science/jpa-00247592}

Submitted on 1 Jan 1991

HAL is a multi-disciplinary open access archive for the deposit and dissemination of scientific research documents, whether they are published or not. The documents may come from teaching and research institutions in France or abroad, or from public or private research centers.
L'archive ouverte pluridisciplinaire HAL, est destinée au dépôt et à la diffusion de documents scientifiques de niveau recherche, publiés ou non, émanant des établissements d'enseignement et de recherche français ou étrangers, des laboratoires publics ou privés. 
Classification

Physics Abstracts

$68.15-05.70 \mathrm{~F}-33.50 \mathrm{D}$

\title{
Fluorescence microscopy evidence for two different LE-LC phase transitions in Langmuir monolayers of fatty acids
}

\author{
S. Akamatsu and F. Rondelez \\ Université Pierre et Marie Curie (Paris VI), Laboratoire Structure et Réactivité aux Interfa- \\ ces $\left(^{*}\right)$, Bâtiment de Chimie Physique, 11 rue Pierre et Marie Curie, 75231 Paris Cedex 05, \\ France
}

(Received 5 March 1991, revised 21 June 1991, accepted 25 June 1991)

\begin{abstract}
Résumé. - Nous avons étudié la transition entre les phases liquide expansé (LE) et liquide condensé (LC) dans les monocouches de Langmuir d'acide myristique (MYA) et d'acide pentadécanoïque (PDA) par des mesures de pression de surface et par des observations en microscopie de fluorescence. Cette transition est toujours du premier ordre mais, suivant la température $T$, la phase LE se transforme en des phases condensées différentes appelées $L_{1} C_{1}$ et $\mathrm{LC}_{2}$. On observe la transition $\mathrm{LE}-\mathrm{LC}_{1}$ seulement en dessous d'une température bien définie $T^{*}$, égale à $24.0 \pm 0.5^{\circ} \mathrm{C}$ pour le MYA et à $35.6 \pm 0.5^{\circ} \mathrm{C}$ pour le PDA. Elle est suivie à plus haute pression par une transition $\mathrm{LC}_{1}-\mathrm{LC} \mathrm{C}_{2}$ se traduisant dans les isothermes par un étroit plateau. Au-dessus de $T^{*}$, on observe la transition $\mathrm{LE}-\mathrm{LC}_{2}$ seule. Ces résultats sont en bon accord avec des travaux récemment publiés par Bibo et Peterson ( $A d v$. Mater. 2 (1990) 309). Les observations par microscopie de fluorescence dans la région de coexistence avec la phase LE montrent que les domaines de la phase $\mathrm{LC}_{1}$ sont circulaires et facilement déformables, alors que les domaines de la phase $\mathrm{LC}_{2}$ sont fortement ramifiés et évoluent très lentement vers leur forme d'équilibre circulaire. $\mathrm{La}$ phase $\mathrm{LC}_{1}$ est clairement un fluide de faible viscosité, alors que la phase $\mathrm{LC}_{2}$ est beaucoup plus visqueuse et possède des propriétés viscoélastiques.
\end{abstract}

\begin{abstract}
We have studied the liquid expanded (LE)-liquid condensed (LC) phase transition in Langmuir monolayers of myristic (MYA) and pentadecanoic (PDA) acids by extensive surface pressure measurements and fluorescence microscopy observations. Depending on the temperature $T$, the LE phase transforms through first order phase transitions into two different condensed phases called $L_{1} C_{1}$ and $L C_{2}$. The LE-LC 1 transition is observed below a well-defined temperature $T^{*}$ of $24.0 \pm 0.5^{\circ} \mathrm{C}$ for MYA and $35.6 \pm 0.5^{\circ} \mathrm{C}$ for PDA. It is followed at high pressures by a $\mathrm{LC}_{1}-\mathrm{LC}_{2}$ transition which is signaled by a narrow plateau region in the isotherms. Above $T^{*}$, only the $\mathrm{LE}-\mathrm{LC}_{2}$ transition is observed. These results are in good agreement with previous measurements by Bibo and Peterson (Adv. Mater. 2 (1990) 309). Fluorescence microscopy observations in the coexistence region show that the $L C_{1}$ domains are circular and easily deformable, whereas the $\mathrm{LC}_{2}$ domains are highly ramified and evolve very slowly towards their equilibrium circular shape. The $L_{1}$ phase is clearly a low viscous fluid, whereas the $L_{2}$ phase is much more viscous and exhibits viscoelastic properties.
\end{abstract}

$\left(^{*}\right)$ Laboratoire associé au CNRS (URA 1319). 


\section{Introduction.}

It has been recognized very early that monolayers of amphiphiles deposited at the air/water interface can exhibit different physical states. Upon increasing surface density [1, 2], the socalled gas (G), liquid expanded (LE), liquid condensed (LC) and eventually solid (S) phases have been successively observed, in complete analogy with the well-known three-dimensional thermodynamics. The essential parameters are the temperature $T$, the area per molecule $A$ and the surface pressure $I 7$ [3]. Recent careful experiments by Pallas and Pethica [4] on highly purified samples of pentadecanoic acid have proved that the LE-LC transition of fatty acids is first-order. Similar studies have been performed by Albrecht et al. [5] on phospholipid monolayers. The order of this transition, called the main transition by Harkins [2], has been spectacularly confirmed by epifluorescence microscopy observations $[6,7]$ which have shown unambiguously the coexistence of islands of the LC phase in the continuous LE phase. This powerful direct visualization method allows to study a large number of static [8] as well as dynamic $[9,10]$ two-dimensional transformations into monolayers, with micrometric spatial resolution. In a recent paper [11] we have shown that it can be used to investigate the phase diagram of the monolayers. It has the advantage over classical surface pressure isotherms to reveal the growth morphology of the various two-dimensional phases.

In this paper, we present a detailed study of the LE-LC transition for monolayers of two fatty acids, namely myristic (tetradecanoic) (MYA) and pentadecanoic (PDA) acids. Fluorescence microscopy shows that the shape of the growing LC domains is radically different depending on the temperature. At low $T$, the islands are always circular, whereas they are highly ramified [12] above a characteristic temperature $T^{*}$. These growth behaviors are associated with two different first-order phase transitions from the LE phase into two different condensed phases. The possibility of direct optical observation yields new information on the physical properties of these two phases.

\section{Experimental.}

The myristic and the pentadecanoic acids were obtained from Fluka Chem. Hexadecanoic acid (Fluka) was also used in some cases. The samples purity was investigated by thin layer chromatography and found to be higher than $99 \%$. Ten times recrystallization in hexane also did not cause any measurable change in our observations. The monolayers were spread on ultra pure (Milli-Q Organex, Millipore) water at $\mathrm{pH} 2$ to prevent the dissociation of the carboxylic polar head groups. The stability of the monolayer with respect to bulk dissolution was increased by adding calcinated sodium chloride in the water subphase. At fixed pressure $\left(13 \mathrm{mN} \cdot \mathrm{m}^{-1}\right)$ and temperature $\left(22^{\circ} \mathrm{C}\right)$ the material losses per minute were $0.5 \mathrm{~mol} \%$ without salt and dropped to $0.35 \mathrm{~mol} \%$ in the presence of $1 \mathrm{M} \mathrm{NaCl}$ for a MYA monolayer; they were negligible for PDA.

The fatty acids were first dissolved in a volatile mixture of chloroform (Uvasol, Merck)/ethanol (pro analysi, Merck) (9/1), in concentrations of the order of $10^{-3}$ mol.1 ${ }^{-1}$. Small droplets of this solution were then deposited with a Hamilton syringe onto the water surface. The Langmuir Teflon trough $\left(8 \times 15 \mathrm{~cm}^{2}\right)$ was equipped with a sweeping barrier. Compression rates were $3 \pm 0.1 \AA^{2} \cdot \min ^{-1}$ per molecule, and areas per molecule between $60 \AA^{2}$ and $19 \AA^{2}$ were investigated. Typical measuring accuracy was $0.5 \AA^{2}$ per molecule. The surface pressure measurements were performed with a Wilhelmy platinum plate and were accurate within $0.1 \mathrm{mN} \cdot \mathrm{m}^{-1}$. The trough was thermostated at temperatures ranging from $6 \pm 0.1{ }^{\circ} \mathrm{C}$ to $38 \pm 0.1{ }^{\circ} \mathrm{C}$ with a water circulation bath. During the fluorescence microscopy observations, the water surface was protected from air pollution and convections 
by a glass plate. In order to reduce water evaporation and the possibility of Rayleigh-Bénard thermal convections in the trough, the temperature of that cover glass was maintained $1{ }^{\circ} \mathrm{C}$ above the trough temperature by adjusting the intensity of the electrical current through its transparent $\mathrm{SnO}_{2}$ coating.

To allow fluorescence microscopy observations, the monolayer was doped with a fluorescent dye, NBD-HDA [4-hexadecylamino-7-nitrobenz-2-oxa-1, 3-diazole], purchased from Molecular Probes Inc., U.S.A. The addition of $1 \mathrm{~mol} \%$ of this dye within the monolayer induces a shift of $0.2 \mathrm{mN} \cdot \mathrm{m}^{-1}$ and $0.5 \AA^{2}$ per molecule in the pressure and the area of the LELC transition, respectively [11]. Since the usual concentration in our experiments is $0.1 \mathrm{mol \%}$, the perturbation remains extremely weak, so that the gross features of the phase diagram are not sensitively affected $[4,13]$. We used a metallurgical Polyvar-Met (ReichertJung) microscope equipped for fluorescence illumination, with excitation at $460 \mathrm{~nm}$ and detection at $525 \mathrm{~nm}$. The fluorescent light was imaged onto a SIT Vidicon camera (Lhesa Electronics) coupled to a T.V. monitor and eventually recorded on VHS tapes. Total magnification was $200 \mathrm{x}$ and spatial resolution was about $3 \mu \mathrm{m}$ with a $20 \mathrm{x}$ objective of 0.4 numerical aperture.

\section{Results.}

1. SURFACE PRESSURE ISOTHERMS. - Three typical surface pressure $(\Pi)$ isotherms of MYA monolayers, corresponding to the temperatures of 10,17 and $25^{\circ} \mathrm{C}$ respectively, are shown in figure 1 . In all cases, $\Pi$ increases from an essentially zero value at an area per molecule of $47 \pm 2 \AA^{2}$ up to a finite value $\Pi_{\mathrm{t}}$ at an area per molecule $A_{\mathrm{t}}$. In this region, the monolayer is in

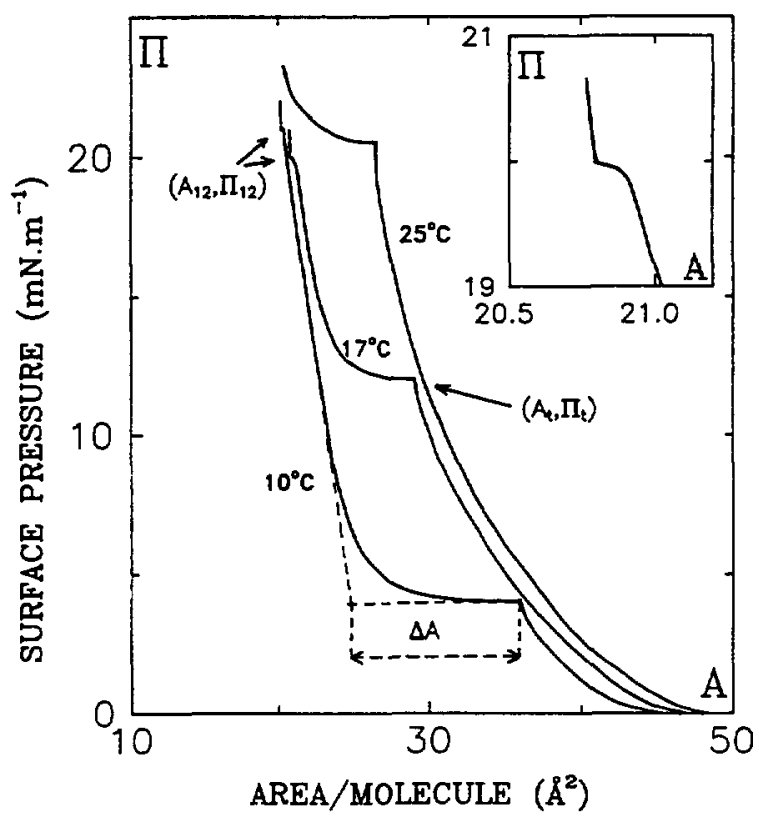

Fig. 1. - Surface pressure isotherms of MYA monolayers at 10,17 and $25^{\circ} \mathrm{C}$. The arrows show the transition surface pressures $\Pi_{\mathrm{t}}$ and $\Pi_{12}$ and the corresponding areas per molecule $A_{\mathrm{t}}$ and $A_{12}$. The dashed lines indicate how the tangent method was used to estimate the variation of area per molecule $\Delta A$ during the LE-LC transition. The small insert is a blow-up of the high pressure region. 


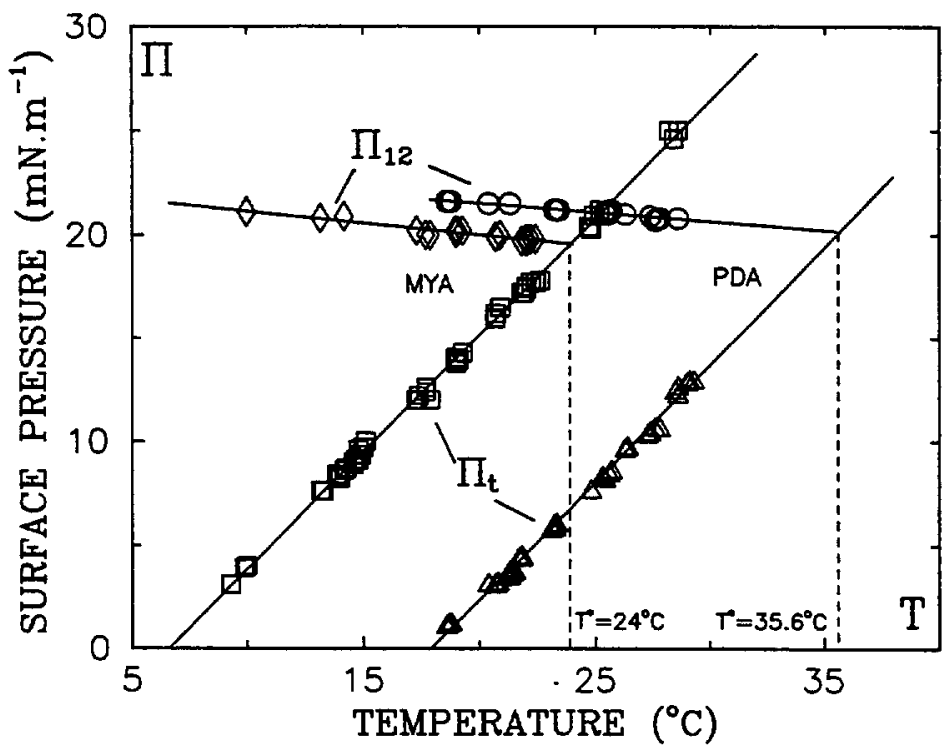

Fig. 2. - Transition surface pressures $\Pi_{1}$ (MYA $(\square)$; PDA $\left.(\Delta)\right)$ and $\Pi_{12}$ (MYA $(\diamond)$; PDA $(0)$ ) versus temperature. $\Pi_{\mathrm{t}}$ corresponds to the onset of the LE-LC ${ }_{1}$ transition below $T^{*}$ and of the LE-LC transition above $T^{*}$, whereas $\Pi_{12}$ corresponds to the $\mathrm{LC}_{1}-\mathrm{LC} \mathrm{C}_{2}$ transition. The solid straight lines result from least square fits. Linear extrapolations to zero surface pressure yield triple point temperatures $T_{0}$ of $6.6^{\circ} \mathrm{C}$ and $17.9{ }^{\circ} \mathrm{C}$ for $\mathrm{MYA}$ and PDA respectively. Intersection points between $\Pi_{\mathrm{t}}$ and $\Pi_{12}$ linear laws define the temperature $T^{*}$ separating the $\mathrm{LE}-\mathrm{LC} \mathrm{C}_{1}$ regime from the LE-LC $\mathrm{C}_{2}$ regime. We obtain $T^{*}=24.0 \pm 0.5^{\circ} \mathrm{C}$ and $35.6 \pm 0.5^{\circ} \mathrm{C}$ for MYA and PDA respectively.

the homogeneous LE state. At $\Pi_{t}$, the slope of the isotherm changes abruptly, which marks the onset of the LE-LC transition. These values are temperature dependent, e.g. at $T=10^{\circ} \mathrm{C}, \quad \Pi_{\mathrm{t}}=4.0 \mathrm{mN} \cdot \mathrm{m}^{-1}$ and $A_{\mathrm{t}}=36.0 \AA^{2}$ per molecule, whereas at $T=17^{\circ} \mathrm{C}$, $\Pi_{\mathrm{t}}=12.0 \mathrm{mN} \cdot \mathrm{m}^{-1}$ and $A_{\mathrm{t}}=29.0 \AA^{2}$ per molecule. Upon further compression, the isotherm stays flat, indicating a first-order transition [4]. The high density end of this transition is signalled by a sharp increase in the surface pressure and occurs around $24 \pm 2 \AA^{2}$ per molecule. At even higher surface densities, the shape of the isotherms is markedly different depending on temperature. In figure 1, a narrow plateau is observed at a pressure $\Pi_{12}$ of $21.1 \mathrm{mN} \cdot \mathrm{m}^{-1}$ at $T=10^{\circ} \mathrm{C}$ and of $20.2 \mathrm{mN} \cdot \mathrm{m}^{-1}$ at $T=17{ }^{\circ} \mathrm{C}$, but is absent at $25^{\circ} \mathrm{C}$.

In figure 2 , one can see the temperature dependence of the surface pressures $\Pi_{\mathrm{t}}$ and $\Pi_{12}$ for both PDA and MYA. In the explored temperature range, $\Pi_{\mathrm{t}}$ increases linearly with temperature and obeys the equation $\Pi_{\mathrm{t}}=m_{\mathrm{t}}\left(T-T_{0}\right)$, where $T_{0}$ is the temperature of the G-LE-LC triple point [14]. The values found by least square analysis are $T_{0}=6.6 \pm 0.3{ }^{\circ} \mathrm{C}$ and $m_{\mathrm{t}}=1.13 \pm 0.01 \mathrm{mN} \cdot \mathrm{m}^{-1} \cdot \mathrm{K}^{-1}$ for MYA, and $T_{0}=17.9 \pm 0.3^{\circ} \mathrm{C}$ and $m_{\mathrm{t}}=1.14 \pm 0.05 \mathrm{mN} . \mathrm{m}^{-1} \mathrm{~K}^{-1}$ for PDA. On the other hand, the surface pressure $\Pi_{12}$ for both acids slightly decreases with temperature. The data can be fitted to a linear relationship $\Pi_{12}=m_{12}\left(T-T_{0}^{12}\right)$, with $\quad m_{12}=-0.11 \pm 0.07 \mathrm{mN} \cdot \mathrm{m}^{-1} \mathrm{~K}^{-1} \quad$ and $T_{0}^{12}=179 \pm 12{ }^{\circ} \mathrm{C}$ for MYA, and $m_{12}=-0.086 \pm 0.07 \mathrm{mN} \cdot \mathrm{m}^{-1} \cdot \mathrm{K}^{-1}$ and $T_{0}^{12}=254 \pm 13^{\circ} \mathrm{C}$ for PDA. Using the above equations for $\Pi_{12}$ and $\Pi_{t}$, one finds that this plateau should disappear above a temperature $T^{*}$ of $24.0 \pm 0.5{ }^{\circ} \mathrm{C}$ for MYA and of $35.6 \pm 0.5{ }^{\circ} \mathrm{C}$ for PDA (see also Fig. 2). This is indeed what is observed in the MYA isotherms shown in figure 1. 
Well-defined isotherms are more delicate to obtain with PDA because of the much higher $T^{*}$ temperature.

The narrow plateau region at high pressures is indicative of a phase transition between two condensed phases that we will call $\mathrm{LC}_{1}$ and $\mathrm{LC}_{2}$. Below $T^{*}$, there are two successive phase transitions, namely $\mathrm{LE}-\mathrm{LC}_{1}$ at low pressure followed by a $\mathrm{LC}_{1}-\mathrm{LC}_{2}$ transition at high pressure. On the contrary, above $T^{*}$, there is a direct $\mathrm{LE}-\mathrm{LC}_{2}$ transition.

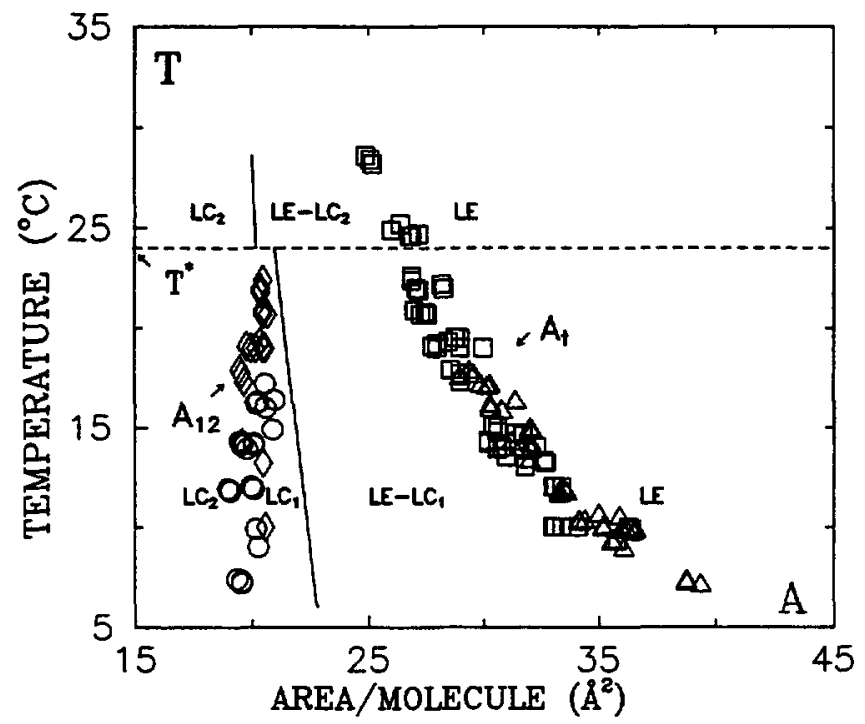

Fig. 3. - Temperature versus areas per molecule $A_{\mathrm{t}}\left(\mathrm{MYA}(\square) ; \operatorname{PDA}(\triangle)\right.$ ) and $A_{12}(\mathrm{MYA}(\diamond) ; \operatorname{PDA}$ (O)). For PDA, the temperature scale has been shifted by $11.3^{\circ} \mathrm{C}$ (see text for details). $A_{\mathrm{t}}$ corresponds to the area per molecule at the onset of the $\mathrm{LE}-\mathrm{LC}_{1}$ (below $T^{*}$ ) and of the LE-LC (above $T^{*}$ ) transitions. $A_{12}$ corresponds to the $\mathrm{LC}_{1}-\mathrm{LC}_{2}$ transition and is only defined below $T^{*}$. The two solid lines mark the high density side of the coexistence curve for the LE-LC 1 and LE-LC phase transitions below and above $T^{*}$ respectively and are just guides to the eye.

Figure 3 shows the temperature dependence of the areas per molecule $A_{\mathrm{t}}$ and $A_{12}$, corresponding to the surface pressures $\Pi_{\mathrm{t}}$ and $\Pi_{12}$, for both MYA and PDA. Below $T^{*}, A_{\mathrm{t}}$ decreases strongly when $T$ increases, whereas $A_{12}$ is more or less unchanged. The width of the homogeneous $\mathrm{LC}_{1}$ region, delimited by the $A_{12}$ line and the high density side of the LE$\mathrm{LC}_{1}$ transition (represented by a straight line in Fig. 3), decreases when $T$ is increased, and vanishes at $T^{*}$. Above $T^{*}$, the $\mathrm{LE}$ phase directly transforms into the $\mathrm{LC}_{2}$ phase.

2. FLUORESCENCE MICROSCOPY. - In parallel with the isotherm measurements, we have performed fluorescence microscopy observations of the growing condensed domains in the LE-LC coexistence region. Figure 4 displays a micrograph of a PDA monolayer at $20^{\circ} \mathrm{C}$, corresponding roughly to the middle of the plateau of transition. The contrast between the phases is due to the partial segregation of the dye out of the condensed phase : the LE phase is bright, while the $\mathrm{LC}$ phase is dark. Isolated $\mathrm{LC}_{1}$ domains nucleate in a circular shape which they keep until the distance between nearest neighbors becomes comparable to the domain radius (of the order of 100 to $200 \mu \mathrm{m}$ ). At smaller distances, the domains interact more strongly and get easily distorted, showing that they are fluid-like (Fig. 4a). An additional proof of this property is the ability of immediate deformation under shear stress. When one 


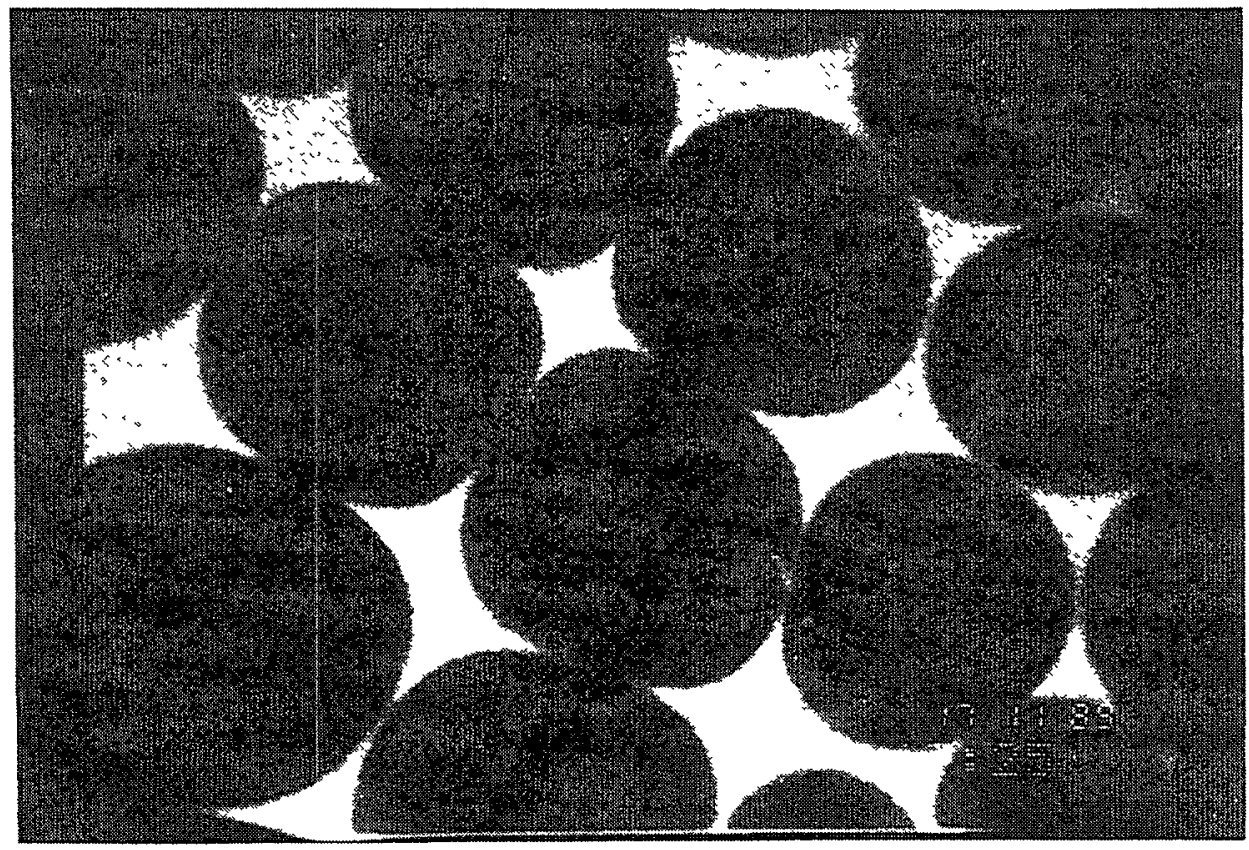

a)
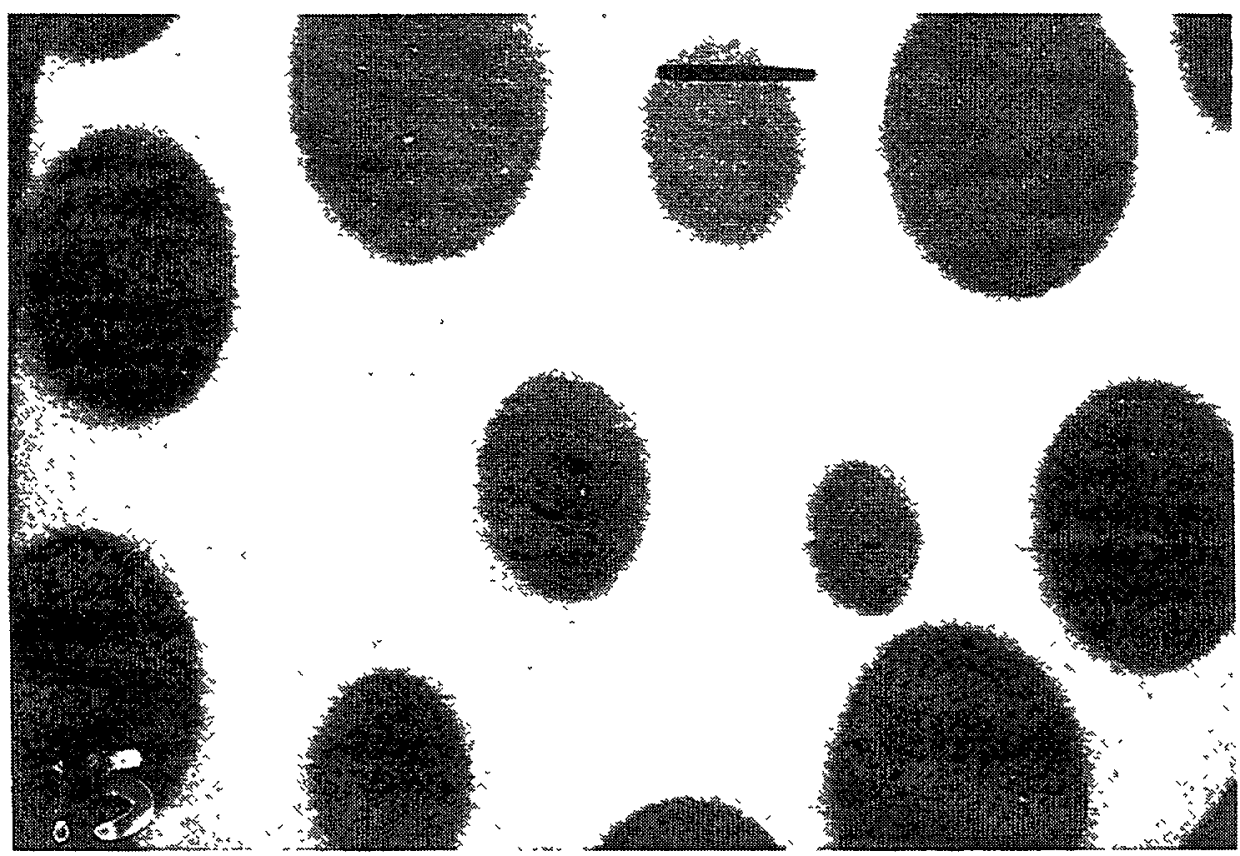

b)

Fig. 4. - Fluorescence microscopy micrographs of liquid condensed $\left(\mathrm{LC}_{1}\right)$ domains (dark disks) growing in the LE continuous phase (bright background) for a PDA monolayer at $20^{\circ} \mathrm{C}$ in normal conditions (Fig. 4a) and under external flow (Fig. 4b). In figure 4a, the domain distortion from circular shape is due to the interactions between neighbours, whereas in figure $4 \mathrm{~b}$, the elliptic shape is induced by shear stress. Total magnification was $200 \mathrm{x}$. The scale is given by the little bar which is $100 \mu \mathrm{m}$ in length. 


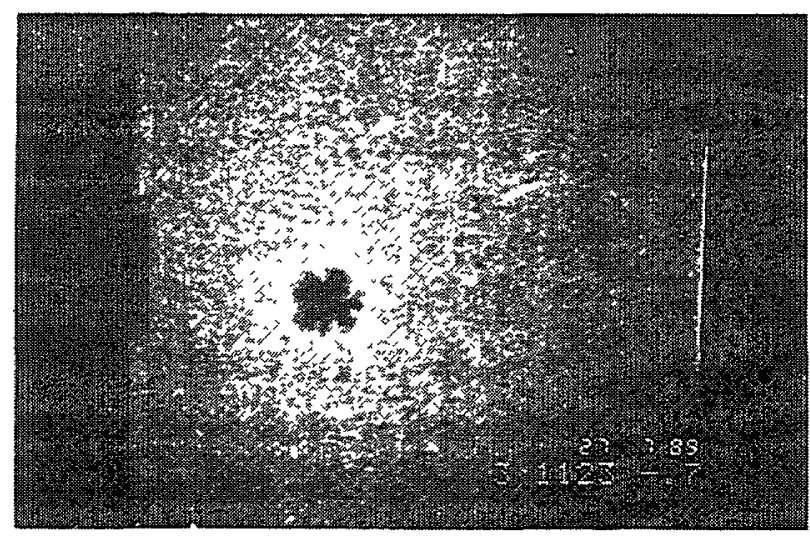

a)

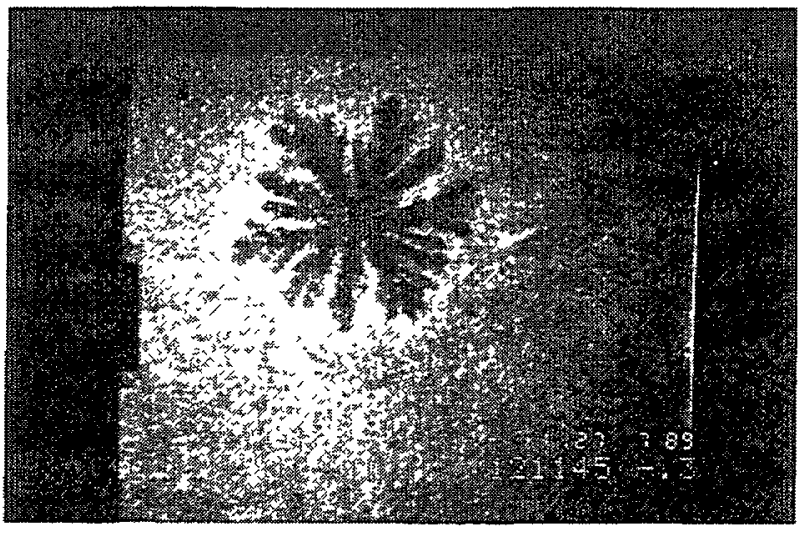

b)

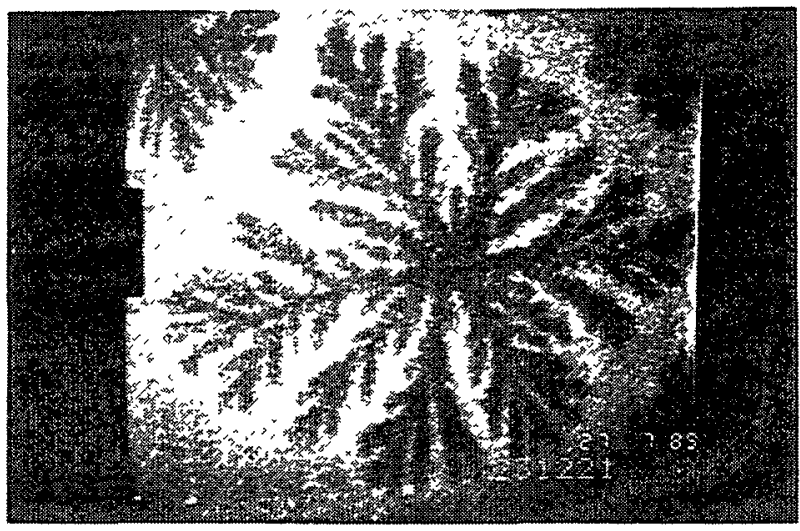

c)

Fig. 5. - Fluorescence microscopy images of a liquid condensed $\left(\mathrm{LC}_{2}\right)$ domain (dark disks) growing in the LE continuous phase for a MYA monolayer at $25^{\circ} \mathrm{C}$. The three snapshots correspond to different stages of the unstable growth of the domain during the transition. The little black bar corresponds to $100 \mu \mathrm{m}$ in length. 


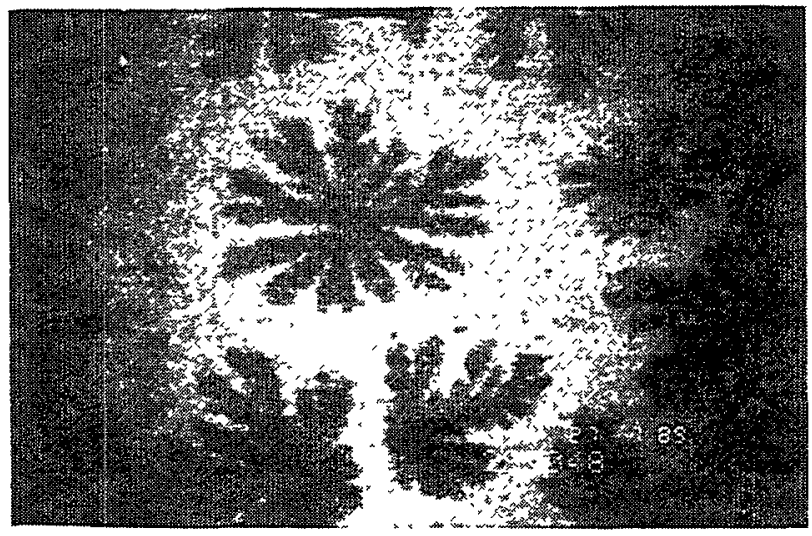

a)

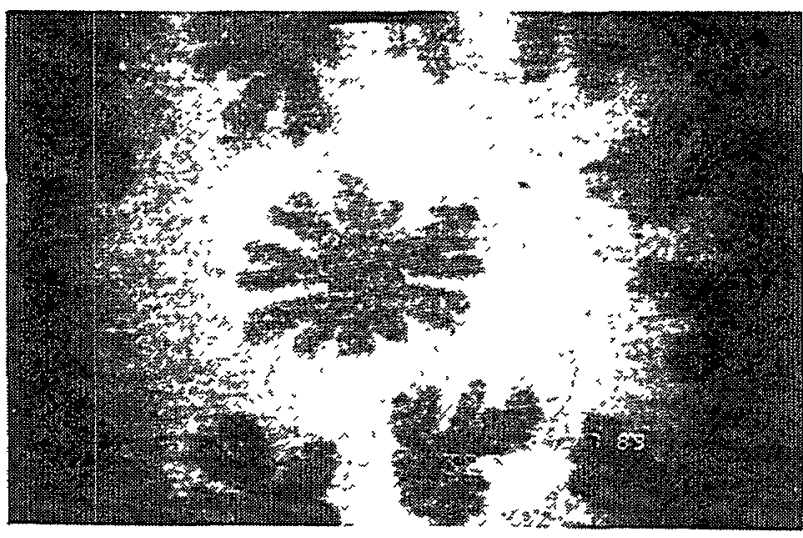

b)

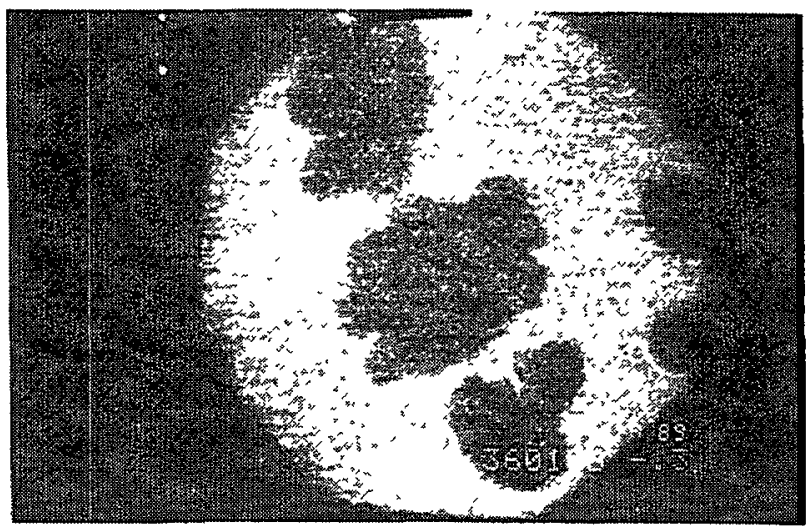

c)

Fig. 6. - Shape relaxation of a fractal $\mathrm{LC}_{2}$ domain in a PDA monolayer at $36^{\circ} \mathrm{C}:$ just after stopping compression (6a), after $10 \mathrm{~min}(6 \mathrm{~b})$, and after 1 hour (6c). The little black bar corresponds to $100 \mu \mathrm{m}$ in length. 
blows slightly over the surface, the domains become elliptic (Fig. 4b), but they recover their initial circular shape as soon as the stress is removed. This behavior is typical of PDA below $35.6 \pm 0.5{ }^{\circ} \mathrm{C}$, and of MYA below $24.0 \pm 0.5^{\circ} \mathrm{C}$.

At higher temperatures, the morphology of the domains is strikingly different. Figure 5 displays three snapshots taken at different stages of the transition for a MYA monolayer at $25^{\circ} \mathrm{C}$. In this situation, the $\mathrm{LC}_{2}$ domains nucleate as distorted circles with a few hardly visible bumps. As they grow above $50 \mu \mathrm{m}$ in diameter, they evolve towards highly ramified patterns. At the beginning of the ramification, 5 or 6 primary branches grow independently. Their width is of about $25 \mu \mathrm{m}$. The tip of each branch becomes rapidly unstable and splits into two new branches. The number of fingers increases by tip-splitting until the domain reaches its maximum size $(\approx 600 \mu \mathrm{m}$ in $\mathrm{Fig}$. $5 \mathrm{c}$ ). These random ramified patterns are fractal, and the associated Hausdorf exponent is $1.76 \pm 0.09$, as obtained by image analysis using four different calculation methods $[12,15]$. These fractal domains are much more rigid than the circular ones observed at low temperature. When two of these objects come into contact, they will rotate as gear wheels and there is no trend for immediate rearrangement on the short time scale of the collision process. Long time shape relaxation does exist however : when stopping the compression in the middle of the coexistence region, a ramified pattern will coarsen over a time scale of tens of minutes and will eventually reach a quasi-circular shape after one hour. One can see in figure 6a-c that the ramifications slowly disappear, becoming single smooth bumps. We have carefully checked that this relaxation is due to internal rearrangements and not to dissolution in the subphase. Indeed, the total area of a single island is conserved ( $\pm 10 \%$ ) during the relaxation process. Such unstable growth is observable at all the experimentally accessible compression rates $A^{-1} \frac{\mathrm{d} A}{\mathrm{~d} t}=5 \times 10^{-4}-0.3 \mathrm{~s}^{-1}$ At the highest compression rates, well-developed figures with many ramifications are observed, whereas at the lowest compression rates, the duration of the experiments becomes comparable to the characteristic relaxation kinetics discussed above, and the $\mathrm{LC}_{2}$ domains are more aptly described as distorted circles.

For MYA, liquid condensed domains were observed up to a maximum temperature of $32{ }^{\circ} \mathrm{C}$ because of the increased solubility of the monolayer into the subphase at elevated temperatures. For PDA, these problems are much less severe since the hydrocarbon chain is longer than for MYA and fractal growth has been observed from $35.6{ }^{\circ} \mathrm{C}$ up to at least $38^{\circ} \mathrm{C}$, which is the highest temperature accessible with our current setup.

\section{Discussion.}

The above results show that depending on temperature, the LE phase of fatty acid monolayers transforms through first-order phase transitions into two distinct condensed phases, namely $\mathrm{LE}-\mathrm{LC}_{1}$ and $\mathrm{LE}-\mathrm{LC}_{2}$. This confirms the surface pressure studies carried out by Stenhagen [16] in the middle of this century on a large series of long chain fatty acids, and the more recent experiments of Bibo and Peterson [17]. These latter authors show that in the case of MYA, which is directly relevant to the present experiments, the LE phase can transform directly into two phases which they call $L_{2}$ and LS according to the Harkins nomenclature [18]. Based on supplementary information brought by our fluorescence microscopy observations, we have preferred to call them $\mathrm{LC}_{1}$ and $\mathrm{LC}_{2}$ to express the fact that both phases i) can be obtained by compression from the LE phase, and ii) are isotropic liquids, although with different viscosities. The fluorescence microscopy data are in good correspondence with the surface pressure isotherms. In particular, the temperature at which the shape of the growing condensed domains changes from smooth circles to ramified patterns 
is exactly the same as the temperature $T^{*}$ at which the $\mathrm{LE}-\mathrm{LC}_{1}$ transition is replaced by the LE-LC $\mathrm{C}_{2}$ transition.

The LE-LC $\mathrm{C}_{1}$ transition, when it exists, is followed by a $\mathrm{LC}_{1}-\mathrm{LC}_{2}$ transition upon further monolayer compression. This transition is also first-order as evidenced by the existence of a characteristic plateau in the high density region of the surface pressure isotherms. This plateau however is very narrow and has a width of only 0.1 or $0.2 \AA^{2}$ per molecule. Therefore it could be easily mistaken with a mere slope discontinuity. Its existence has been confirmed by separate experiments by Sackmann and coworkers $[5,19]$ on hexadecanoic acid monolayers.

From our observations on MYA and PDA, it appears that the phase diagram is universal for fatty acids. It has already been mentioned in the literature that the $T_{0}$ values are shifted by roughly $10^{\circ} \mathrm{C}$ per each methylene group $[14,20,21]$. As shown in figure 2, the phase diagrams for MYA and PDA are exactly superimposable through a shift of $11.3 \pm 0.6{ }^{\circ} \mathrm{C}$ along the temperature scale. Moreover, our fluorescence microscopy investigations on hexadecanoic acid show that the circular domains corresponding to the $\mathrm{LE}-\mathrm{LC}_{1}$ transition can be nucleated only above a temperature of $29.5 \pm 0.5{ }^{\circ} \mathrm{C}$, i.e. $11.6 \pm 0.5{ }^{\circ} \mathrm{C}$ above the triple point temperature $T_{0}$ of PDA. The analogy between MYA and PDA is particularly visible when plotting $\Pi_{\mathrm{t}}$ and $\Pi_{12} v s . A_{\mathrm{t}}$ and $A_{12}$ respectively : all data points collapse on a single curve (Fig. 7). This is in good agreement with the universal diagram proposed recently by Bibo et al. [22].

The observation by fluorescence microscopy of a coexistence region between the LE and $\mathrm{LC}_{1}$ phases on one hand and between the $\mathrm{LE}$ and $\mathrm{LC}_{2}$ phases on the other hand proves that both of these transitions are first-order. The enthalpy of transition can be derived from the

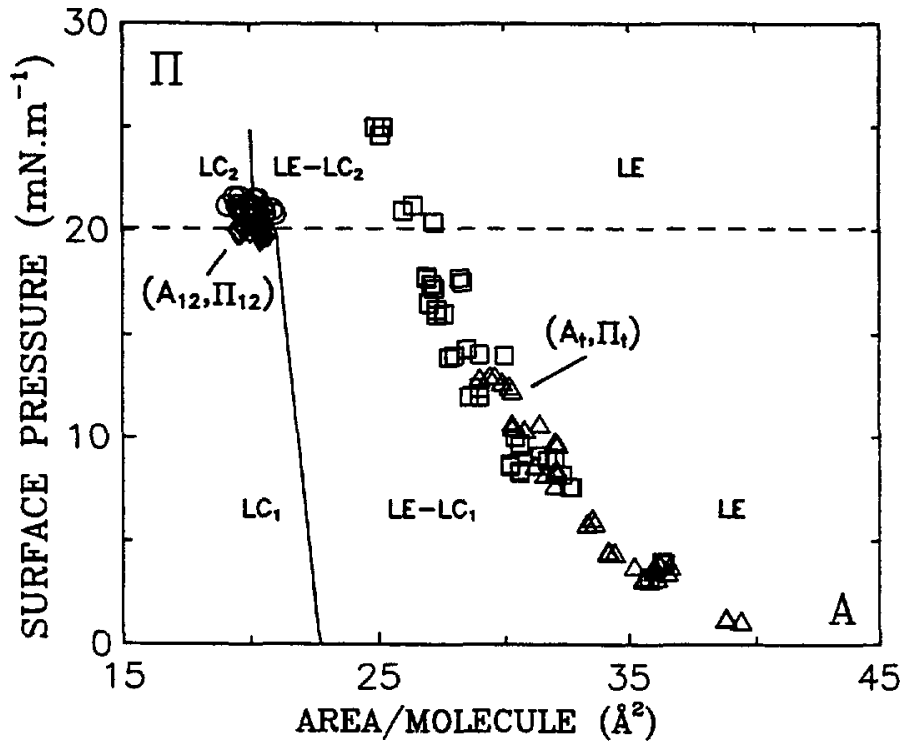

Fig. 7. - Surface pressures $\Pi_{\mathrm{t}}$ and $\Pi_{12}$ versus areas per molecule $A_{1}$ and $A_{12}$ for MYA $(\square, 0)$ and PDA

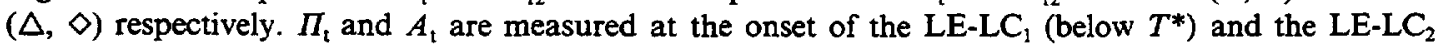
(above $T^{*}$ ) transitions. $\Pi_{12}$ and $A_{12}$ correspond to the $\mathrm{LC}_{1}-\mathrm{LC}_{2}$ transition. The solid lines mark the high density side of the LE-LC $\left(\right.$ below $T^{*}$ ) and the $\mathrm{LE}_{\mathrm{LCC}}$ (above $T^{*}$ ) coexistence curves and are just guides to the eye. 
Clapeyron equation which relates the temperature dependence of $\Pi_{\mathrm{t}}$ with the molecular area change $\Delta A$ during the transition [23] :

$$
\Delta H_{\mathrm{t}}=\Delta A \cdot T \cdot \frac{\mathrm{d} \Pi_{\mathrm{t}}}{\mathrm{d} T}
$$

In this equation the temperature $T$ is expressed in kelvin. Taking $\frac{\mathrm{d} \Pi_{\mathrm{t}}}{\mathrm{d} T}=m_{\mathrm{t}}=1.13 \mathrm{mN} \cdot \mathrm{m}^{-1} \mathrm{~K}^{-1}$ from figure 2, and evaluating $\Delta A$ at each temperature as shown in figure 1 , one can plot $\Delta H_{\mathrm{t}}$ as a function of $T$. In figure 8 , one can see that the data for MYA fall on two different curves on both sides of the $T^{*}$ value of $24^{\circ} \mathrm{C}$. The $\Delta H_{\mathrm{t}}$ discontinuity observed at $T^{*}$ is consistent with the existence of two different molecular conformations in the $\mathrm{LC}_{1}$ and $\mathrm{LC}_{2}$ phases respectively. Extrapolation to $\Delta H_{\mathrm{t}}=0$ allows a rough estimation of the critical temperature $T_{c}$ at which the LE-LC $C_{2}$ transition would eventually become second-order. We obtain a $T_{c}$ value of $39.7 \pm 1{ }^{\circ} \mathrm{C}$ for MYA. Performing optical observation close to $T_{\mathrm{c}}$ would be interesting for future investigations. For instance, it is well known that line tension between the LE and the LC domains falls to zero when the temperature approaches $T_{\mathrm{c}}$. This argument has been used by Suresh et al. [12] to explain the observation of fractals at high temperature. The present experiments show however that this explanation is not necessarily correct : the fractals are rather related to the appearance of the $\mathbf{L C}_{2}$ phase. This is satisfactory because it was difficult to explain how critical point effects could show up as far down as $10^{\circ} \mathrm{C}$ below $T_{c}$.

In figure 8 , we have also shown the data points obtained for PDA (note that the $T$ scale has been shifted by $\left.11.3^{\circ} \mathrm{C}\right)$. In the narrow temperature range investigated $\left(17-29^{\circ} \mathrm{C}\right)$, the

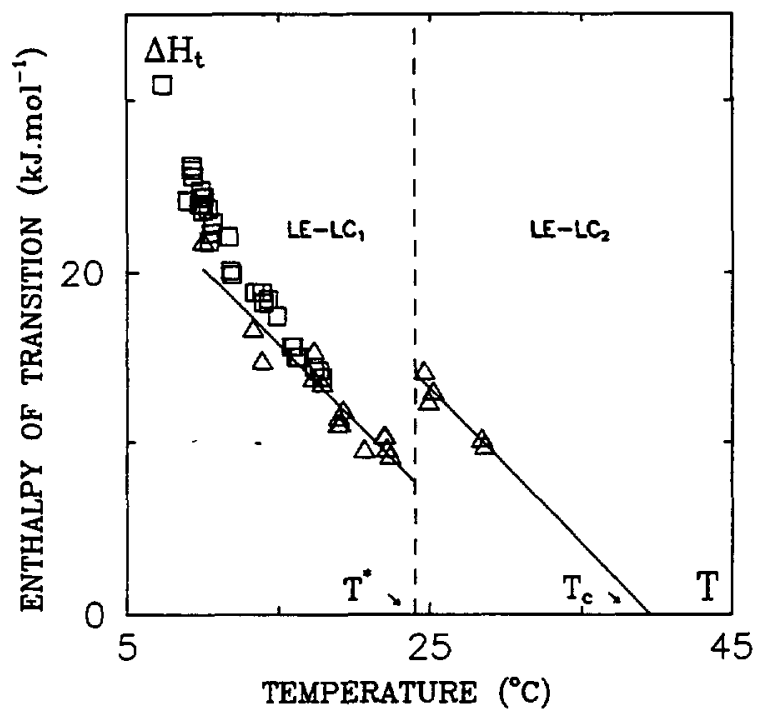

Fig. 8. - Enthalpy $\Delta H_{1}$ of the $L E-L C_{1}$ and LE-LC $C_{2}$ transitions for MYA $(\triangle)$ and PDA $(\square)$ as a function of the temperature $T$. PDA data have been shifted by $11.3^{\circ} \mathrm{C}$ (see text for details). $T^{*}$ is the temperature at which the LE-LC $\mathrm{C}_{1}$ transition is replaced by the $\mathrm{LE}-\mathrm{LC}_{2}$ transition. Straight lines are best fit curves calculated from MYA data only. 
enthalpy for the LE-LC $\mathrm{C}_{1}$ transition appears to be the same as for MYA in the translated $T$ scale. This is consistent with the empirical relationship

$$
\Delta H_{\mathrm{t}}(\mathrm{PDA} ; T)=\frac{T}{T-\Delta T_{0}} \Delta H_{\mathrm{t}}\left(\mathrm{MYA} ; T-\Delta T_{0}\right)
$$

derived from the Clapeyron equation by assuming that

$$
\Delta A(\mathrm{PDA} ; T) \equiv \Delta A\left(\mathrm{MYA} ; T-\Delta T_{0}\right)
$$

This equation predicts a difference of only 4 to $6 \%$ in $\Delta H_{\mathrm{t}}$ between the two acids, which is comparable to our experimental error range.

As suggested by Miller and Möhwald [10], the growth instability which generates the distortion of the $\mathrm{LC}_{2}$ domains is governed by the Mullins-Sekerka mechanism [24]. These patterns are metastable : in order to minimize the total line free energy, they will evolve towards circles, keeping the total area constant. We will use this property to derive information on the physical state of the $\mathrm{LC}_{2}$ phase. There are two mechanisms which can a priori govern the shape relaxation : purely diffusive evaporation-condensation, the so-called Ostwald ripening phenomenon [25], and/or internal hydrodynamic flows [26]. Were the first mechanism dominant, we should observe the growth of the largest islands at the expense of the smallest ones. This was never the case in our experiments. Fluid motions are thus the governing factor, which proves that the $\mathrm{LC}_{2}$ phase is fluid or at least viscoelastic. Since we observe typical relaxation time of the order of 1 hour, the $\mathrm{LC}_{2}$ phase must be highly viscous. By contrast, we have already said above that $\mathrm{LC}_{1}$ domains relax on a time scale of 1 second after a shear flow induced deformation. This fast relaxation prevents the development of unstable fingers. This explains why no ramified patterns are observed during the $\mathrm{LE}-\mathrm{LC}_{1}$ transition.

Our estimations of characteristic relaxation times imply that the viscosity of the $\mathrm{LC}_{1}$ and $\mathrm{LC}_{2}$ phases differ by three orders of magnitude. This is compatible with the surface viscosity data for PDA monolayers at $25^{\circ} \mathrm{C}$ recently reported by Winch and Earnshaw [27]. In the homogeneous $\mathrm{LC}_{1}$ phase at $\Pi=10 \mathrm{mN} \cdot \mathrm{m}^{-1}$, the viscosity, measured by a dynamic light scattering method, is very small, of the order of $10^{-4} \mathrm{mN} . \mathrm{s} . \mathrm{m}^{-1}$, whereas it is three orders of magnitude higher in the $\mathrm{LC}_{2}$ phase, reaching a value of about $10^{-1} \mathrm{mN} . \mathrm{s} . \mathrm{m}^{-1}$ at $\Pi=22.5 \mathrm{mN} \cdot \mathrm{m}^{-1}$ [18]. We must however point out that our observation by fluorescence microscopy of apparent rigidity at short time scales during the collision of two $\mathrm{LC}_{2}$ fractal domains is indicative of a more complex, viscoelastic behavior. This property is also evident in careful measurements performed by Ketterson, Miyano and coworkers [28] : in particular, they have been able to measure a finite elastic shear modulus of the order of $10^{-3} \mathrm{mN}^{-1}$ in the high surface pressure phase of nonadecanoic acid monolayers. In earlier experiments, the same authors had detected no clear elastic behavior for stearic acid [29], which differs from PDA by only 3 additional methylene groups in the aliphatic chain, but it could be that the shear modulus values to be measured were below the detection limit of their experimental setup. At this stage, it seems hazardous to interpret the mechanical behavior of the condensed phases too strongly. Moreover, it is not clear for us if such measurements could be able to distinguish between viscous and plastic flows.

Nowadays, the most popular technique for direct study of the monolayer structures at the microscopic level is in-plane X-ray diffraction. Dutta et al. [30], and Als-Nielsen, Möhwald and coworkers $[31,32]$ have shown that it is possible to detect local order within the condensed phases of fatty acid and phospholipid monolayers using synchrotron radiation. By studying long chain fatty acids such as docosanoic and heneicosanoic acids, Lin et al. [33] and Kenn et al. [34] have shown that the symmetry of the $L_{2}$ (or $L_{1} C_{1}$ ) phase is centered 
rectangular, i.e. distorted hexagonal, whereas the $\mathrm{LS}$ (or $\mathrm{LC}_{2}$ ) phase is hexagonal. In all cases studied so far however, the correlation length of positional order is very small, of the order of $300 \AA$ for the $L C_{2}$ phase, and even much shorter $(\approx 50 \AA)$ for the $L C_{1}$ phase. This supports our finding that the $\mathrm{LC}_{1}$ phase is truly liquid. For the $\mathrm{LC}_{2}$ phase on the other hand, it explains why it is difficult to distinguish, by using the macroscopic properties alone, between a solid structure with a large density of defects, which will exhibit plastic behavior [35], and a highly viscous liquid phase. In addition, electron diffraction observations on phospholipid monolayers transferred on solid substrates suggest that some of these phases are hexatic [36, 37]. It would be interesting to perform X-ray measurements on PDA monolayers at high densities, above the narrow plateau region. Unfortunately, their stability is weak at high pressures and monolayer dissolution is significant over the long time scale $(\approx 30 \mathrm{~min}$ ) necessary for these diffraction experiments [38]. Therefore, we are now considering other amphiphiles which show comparable LE-LC transitions.

\section{Conclusion.}

The combination of isotherm measurements and fluorescence microscopy observations allows to show that the phase diagram of fatty acid monolayers is universal and that surface pressure isotherms of fatty acids with two different chain lengths can be superimposed by using a temperature shift of $11.3 \pm 0.6{ }^{\circ} \mathrm{C}$ per each additional $\mathrm{CH}_{2}$ group. We have also confirmed the existence of two distinct condensed phases $\mathrm{LC}_{1}$ and $\mathrm{LC}_{2}$. Four temperature ranges can be distinguished. Below the so-called G-LE-LC triple point temperature $T_{0}\left(6.6 \pm 0.3^{\circ} \mathrm{C}\right.$ for MYA and $17.9 \pm 0.3^{\circ} \mathrm{C}$ for PDA), the LE phase does not exist, and the $\mathrm{G}$ phase transforms directly into the $\mathrm{LC}_{1}$ condensed phase. Between $T_{0}$ and a temperature $T^{*}\left(24.0 \pm 0.5^{\circ} \mathrm{C}\right.$ for MYA and $35.6 \pm 0.5^{\circ} \mathrm{C}$ for PDA), the $\mathrm{LE}$ phase transforms into the $\mathrm{LC}_{1}$ phase. Upon further compression, there is an additional transition from the $\mathrm{LC}_{1}$ phase to the $\mathrm{LC}_{2}$ phase. This transition is signaled by a narrow plateau in the isotherms and is therefore first-order. Above $T^{*}$, a direct transition from the $L E$ to the $\mathrm{LC}_{2}$ phase is observed and the $\mathrm{LC}_{1}-\mathrm{LC}_{2}$ transition disappears. This is in complete agreement with systematic studies by Bibo and Peterson of the phase diagram of fatty acids with 14 to 22 carbon atoms chain length. By using Clapeyron's law, we have found that the enthalpy of transition should vanish at a critical temperature $T_{\mathrm{c}}$ of about $39.7 \pm 1{ }^{\circ} \mathrm{C}$ for MYA. In principle, the $\mathrm{LE}-\mathrm{LC}_{2}$ transition should exist up to $T_{\mathrm{c}}$, but we have been able to observe it only up to about $32^{\circ} \mathrm{C}$ for MYA because of the reduced monolayer stability at high temperature. By fluorescence microscopy, the $\mathrm{LC}_{1}$ phase is found to grow in the form of highly deformable circular domains. On the contrary, the $\mathrm{LC}_{2}$ islands are ramified and rigid at short time scales. However, since they relax slowly by viscous flow, this phase is viscoelastic, in good agreement with surface theology measurements which show the existence of finite shear moduli in long chain fatty acids at high pressures. The $\mathrm{LC}_{1}$ phase is definitely a true liquid, whereas the nature of the $\mathrm{LC}_{2}$ phase is more open to questions. The fact that the $\mathrm{LC}_{1}-\mathrm{LC}_{2}$ transition is first-order provides no clue for the microscopic structure of the $\mathrm{LC}_{2}$ phase. A clear-cut distinction between a highly viscous liquid and a plastic crystal (or a high defect solid) can only be reached after performing synchrotron X-ray diffraction experiments on PDA monolayers. Recent diffraction experiments on longer fatty acids have shown that many different short-range ordered structures are possible in a narrow range of densities between 19 and $24 \AA^{2}$ per molecule.

\section{Acknowledgements.}

We thank Françoise Billoudet for her help with surface pressure measurements, and we acknowledge helpful discussions with Othman Bouloussa on the properties of fatty acid monolayers. 
We are very grateful to Ian Peterson for his critical reading of the manuscript and for pointing out to us the existence of references [16] [17] and [34].

This work was supported in part by a grant from the Direction of Research, Development and Innovation of Elf-Aquitaine and by a BDI Doctorate position for one of us (S. A.).

\section{References}

[1] Adam N. K., Jessop G., Proc. R. Soc. London A 112 (1926) 364.

[2] Harkins W. D., Boyd E., J. Phys. Chem. 45 (1941) 20.

[3] GaINes G. L. Jr., Insoluble Monolayers at Liquid-Gas Interfaces (Wiley, New-York, 1966).

[4] Pallas N. R., Pethica B. A., Langmuir 1 (1985) 509.

[5] Albrecht O., Gruler H., Sackmann E., J. Phys. France 39 (1978) 301.

[6] Von TsCharner V., MCConnell H. M., Biophys. J. 36 (1981) 409.

[7] Lösche M., Sackmann E., Möhwald H., Ber. Bunsen-Ges. Phys. Chem. 87 (1983) 848.

[8] Weiss R. M., MCConnell H. M., Nature 10 (1984) 5972.

[9] Miller A., KNoli W., Mohwald H., Phys. Rev. Lett. 56 (1986) 2633.

[10] Miller A., Möhwald H., J. Chem. Phys. 86 (1987) 4258.

[11] Moore B. G., Knobler C. M., Akamatsu S., Rondelez F., J. Phys. Chem. 94 (1990) 4588.

[12] SUResh K. A., NrtTMANN J., Rondelez F., Europhys. Lett. 6 (1988) 437.

[13] Winch P. J., Earnshaw J. C., J. Phys. Cond. Matter. 1 (1989) 7187.

[14] Kellner M. J., Müller-Landau F., Cadenhead D. A., J. Colloid Interface Sci. 82 (1978) 597.

[15] AKamatsu S., Rondelez F., to be published (1991).

[16] STENhageN E.. in Determination of organic structures by physical methods, Chapter 8, Eds E. A. Braude \& F. C. Nachod (Academic Press, New York, 1955).

[17] Bibo A.-M., Peterson I. R., Adv. Mater. 2 (1990) 309.

[18] Boyd E., Harkins W. D., J. Am. Chem. Soc. 61 (1939) 1188.

[19] Fischer A., SaCKMANn E., J. Coll. Interface Sci. 112 (1985) 1.

[20] Bouloussa O., Dupeyrat M., Biochim. Biophys. Acta 896 (1987) 239.

[21] Pallas N. R., Pethica B. A., J. Chem. Soc. Faraday Trans. 83 (1987) 585.

[22] Bibo A.-M., Knobler C. M., Peterson I. R., to appear in J. Phys. Chem. (1991).

[23] Rondelez F., Baret J. F., Bois A. G., J. Phys. France 48 (1987) 1225.

[24] Mullins W. W., Sekerka R. F., J. Appl. Phys. 34 (1963) 323. Mullins W. W., Sekerka R. F., J. Appl. Phys. 35 (1964) 444.

[25] KAHLWeIT M., Adv. Colloid Interface Sci. 5 (1975) 1.

[26] WitTEN T., On Growth and Form, Proceedings of NATO summer school, Cargese, Corsica, July 1985 (Martinus Nijhof, The Hague, 1986).

[27] Winch P. J., Earnshaw J. C., J. Phys. Cond. Matter 2 (1990) 8499.

[28] Abraham B. M., Mryano K., Xu S. Q., Ketterson J. B., Phys. Rev. Lett. 49 (1982) 1643.

[29] Abraham B. M., Ketterson J. B., Miyano K., Kueny A., Phys. Rev. Lett. 75 (1981) 3137.

[30] Barton S. W., Thomas B., Flom E., Rice S. A., Lin B., Peng J. B., Ketterson J. B., Dutta P., J. Chem. Phys. 89 (1988) 2257.

[31] Kjaer K., Als-Nielsen J., Helm C. A., Tippman-Krayer P., Móhwald H., J. Phys. Chem. 93 (1989) 3200.

[32] Mónwald H., Ann. Rev. Phys. Chem. (1990) 441.

[33] Lin B., Shih M. C., Bohanon T. M., ICE G. E., Dutta P., Phys. Rev. Lett. 65 (1990) 191.

[34] Kenn R. M., Bohm C., Bibo A.-M., Peterson I., Mohwald H., Als-Nielsen J., Kuaer K., $J$. Phys. Chem. 95 (1991) 2092.

[35] Gaub H. E., Moy V. T., McConnell H. M., J. Phys. Chem. 90 (1986) 1721.

[36] Sackmann E., Fischer A., Frey W., in Physics of Amphiphilic Layers, Springer Proceedings in Physics, Vol. 21 (Springer-Verlag, Berlin, 1987).

[37] Helm C. A., Möhald H., KJaer K., Als-Nielsen J., Biophys. J. 52 (1987) 381.

[38] BARTON S. W., private communication. 


\title{
Revue de Livres
}

\section{Physique Atomique}

\author{
B. HELD
}

Masson, 1991, Collection Enseignement de la Physique, 228 p., 139 FF, ISBN 2-225-82432-0.

Cet ouvrage a de quoi surprendre car il n'est pas habituel de présenter la physique atomique au niveau d'un enseignement de premier cycle avec un tel parti pris historique. Dès le premier chapitre retraçant les différentes étapes de l'évolution des idées concernant les atomes, de la Grèce antique à l'époque moderne, le ton est donné. Dans le même esprit historico-déductif, mais de façon plus spécifique, sont abordés les aspects discontinus du rayonnement (corps noir et loi de Planck, effet photo-électrique et théorie d'Einstein, effet Compton). Cette première introduction des idées quantiques permet de passer à l'exposé des théories de la structure de l'atome et des expériences qui y mènent; d'abord le modèle de Rutherford et la diffusion des particules chargées, les niveaux d'énergie et l'émission de rayonnement ; puis la théorie de Bohr de l'atome d'hydrogène. Transition en douceur vers la mécanique ondulatoire de de Broglie et l'équation de Schrödinger, puis examen de quelques solutions (états « $s$ » et «p»), introduction du moment angulaire, du spin et des conséquences de l'application d'un champ magnétique, et pour terminer, principe de Pauli appliqué à la classification périodique des éléments.

A la lecture de ce court résumé, on comprend qu'il ne s'agit pas là d'un traité de physique théorique. De plus, cette histoire de la physique atomique s'arrête peu après 1925 , en tout cas avant Dirac. C'est sans doute un peu court mais l'ouvrage est facile à lire et la description détaillée des principales expériences, leur mise en équations puis leur résolution concrète sur des exemples simples, de la détermination des grandeurs fondamentales de la physique atomique, nombre d'Avogadro, charge et masse de l'électron à l'explication de l'effet Zeeman normal, a un côté assez rafraîchissant, de même que le bref chapitre exposant la théorie de la relativité restreinte et les notices biographiques d'une bonne centaine de personnages de l'antiquité à la première moitié du $\mathrm{XX}^{\mathrm{e}}$ siècle.

\section{P. ManNeville (Saclay).}

\section{Introduction to Nonlinear Spectroscopy}

M. D. LeVENSON and S. S. Kano.

Academic Press, 299 p., \$39.50.

Though nonlinear spectroscopy is now a well-matured field there is still a vast amount of theoretical and experimental research going on in this field. Nonlinear optical processes are characterized by the nonlinear dependence on incident intensity so that more intense the incident light is, the greater is the ease of observing such processes. It is therefore not surprising that the subject of nonlinear optics was born soon after the invention of the laser. However it is only with the availability of tunable lasers that it became possible to exploit these processes to obtain new information not accessible from conventional spectroscopy as well as to make precision measurements such as in Doppler-free spectroscopy. During the past three decades there has been an enormous growth in the area.

Introduction to Nonlinear Spectroscopy is a revised edition of the successful 1982 edition with the same title. The 1982 edition was meant to « unify the presentation of the most useful nonlinear spectroscopy techniques at a level accessible to graduate students and spectroscopists unfamiliar with nonlinear optics ». According to the feedback to the author from the users, the level of the book turned out to be far from « introductory "! The new edition has undergone extensive revision and some new material has 
been added. The book gives an excellent account of the principles and experimental methods of nonlinear spectroscopy. It is made up of seven chapters of which the first two provide a theoretical introduction and the approach is semiclassical. The remaining chapters cover saturation spectroscopy, coherent Raman spectroscopy, multiphoton absorption, optical coherent transients, sources for linear and nonlinear spectroscopy. The most important addition is the inclusion of over fifty problems with answers. This is an attractive feature and makes the book well suited for adoption for a graduate course in nonlinear spectroscopy.

The book is well produced and is a valuable introduction to newcomers in the field and is warmly recommended.

T. ThirunamachandRan. 